\title{
Design of a questionnaire for evaluating the quality of life of postpartum women (PQOL) in China
}

\author{
Sui-Zan Zhou $\cdot$ Xiao-Li Wang $\cdot$ Yan Wang
}

Accepted: 8 March 2009/Published online: 25 March 2009

(c) The Author(s) 2009. This article is published with open access at Springerlink.com

\begin{abstract}
Objective To design an instrument for measuring quality of life (QOL) of postpartum women in China 0-12 months after delivery.

Methods A standardized procedure included the following activities: (1) item pool development by in-depth interview and focus group discussion with postpartum women, consultation with experts, participant observation, and literature review; (2) item pool modification by experts and postpartum women; (3) item selection used multiple methods including expert scoring, factor analysis, coefficient of variation, item-removed Cronbach's alpha, itemexpected domain correlation, item-unexpected domain correlation and test-retest correlation analysis, based on the data of item pool test among women at 0-12 months after childbirth and maternal health experts.

Results More than 167 items were generated, of which 101 were considered suitable for the questionnaire pool. Ten experts and 15 women then revised them. The 101revised-item pool was tested on 200 women and ten experts scored the importance of each item. Based on these data, 40 items referring to child care, physical function, psychological function, and social support were selected for the final questionnaire.

Conclusions This was the first questionnaire for evaluating postpartum QOL of women in China. We need to do additional fieldwork to further establish its validity and reliability.
\end{abstract}

S.-Z. Zhou $\cdot$ X.-L. Wang $(\bowtie) \cdot$ Y. Wang Department of Child, Adolescent and Women's Health, School of Public Health, Peking University, No. 38 Xueyuan Road, 100191 Beijing, People's Republic of China

e-mail: xlwang@bjmu.edu.cn
Keywords Postpartum women · Quality of life · Questionnaire · Reliability · Validity

\begin{tabular}{|c|c|}
\hline \multicolumn{2}{|c|}{ Abbreviations } \\
\hline QOL & Quality of life \\
\hline PQOL & $\begin{array}{l}\text { Questionnaire for evaluating the quality } \\
\text { of life of postpartum women }\end{array}$ \\
\hline WHOQOL & $\begin{array}{l}\text { World Health Organization quality of } \\
\text { life scale }\end{array}$ \\
\hline MGI & Mother-generated index \\
\hline MAPP-QOL & Maternal postpartum quality of life \\
\hline
\end{tabular}

\section{Introduction}

In recent years, experts have become increasingly aware of the importance of postpartum health care. Glazener et al. [1] found that few women at postpartum check-ups were entirely healthy. Also, the postpartum health of the mothers had a direct impact on the development of their children, with the children of less healthy mothers developing less well [2].

The health problems of postpartum women are numerous and the causes are multi-factorial. Severe impairments to daily activities caused by postpartum anemia, infection, and bleeding are occurring less commonly [3]. The hazards caused by some chronic conditions, however, such as postpartum sexual dysfunction [4], abdominal pain [5], perineal pain [6], fecal incontinence [7], and urinary incontinence [8] are being increasingly recognized. In addition, postpartum depression is being increasingly recognized as having a significant impact on the health of women after childbirth [9]. With fewer peripartum deaths and less severe postpartum morbidity, it is now recognized 
that non-medical factors such as changing social roles, environmental adaptation, interpersonal relationships, psychological disorders, and other social problems after childbirth have become important determinants of the health of postpartum women. So, any single morbidity or mortality indicator is inadequate to reflect postpartum women's overall health.

To assess disorders with such complex causes, people have paid increasing attention to "quality of life" ("QOL" for short), which is defined by WHO as: "an individual's perception of his/her position in life in the context of the culture and value systems in which he/she lives, and in relation to his/her goals, expectations, standards and concerns" [10]. QOL has been widely used as a standard measure of health outcomes in different types of research, such as QOL surveys in different populations [11], randomized controlled clinical trials [12], community intervention programs [13], optimization of health resource distribution [14], and health influence factor studies [15].

QOL measures may be generic or specific [16]. Generic measures, such as the World Health Organization quality of life scale (WHOQOL) [17], are designed to be broadly applicable across types and severities of diseases, across different medical treatments or health interventions, and across demographic and cultural subgroups; specific measures are designed for a particular disease (also named "disease-specific" measures, such as the QOL scales for cancers [18-20] and those for chronic diseases [21, 22]), but can also be specific to a particular type of person or an age group (also named "population-specific" measures, such as maternal QOL measures [23]). Compared to generic measures, specific measures are more specific to a certain group to detect and measure important changes. In other words, specific instruments may have higher content validity and higher construct validity, but lower generalizability.

Symon et al. designed the first specific QOL scale for postpartum women, the mother-generated index (MGI) in 2001 [24]. MGI is an open subjective self-administered scale. There are some obvious shortcomings of this kind of tool $[25,26]$ : even helped by investigators, participants still need to have sufficient cognitive skills to understand the questions well and write informative answers, and the answers might be easily influenced by the environment and emotional state of the participants. These shortcomings have restricted the use of this scale, especially in some developing countries, including China. Recently, Hill et al. [23] developed a new instrument (MAPP-QOL) to measure maternal quality of life during the early postpartum period. However, validity of this instrument to assess postpartum QOL among Chinese women was uncertain.

Our study was conducted from 2004 to 2006 to design a specific, valid, and reliable instrument for measuring QOL of postpartum women in China $0-12$ months after delivery (PQOL), consistent with the new needs and changes introduced by childbirth. In this paper, we present and discuss the design procedure of the PQOL.

\section{Methods}

This study was approved by the ethics committee of Peking University. Participants were informed of the purpose of the study, that participation was voluntary and that information received would be kept confidential.

The methods followed a well-established model used to design specific QOL measures, including three phases: (1) item pool development, (2) item pool modification, and (3) item selection.

\section{Item pool development}

The first phase was to attain content validity, which is the extent to which a measure reflects the specific intended area of content [27]. The following five qualitative methods were used to collect the issues which were important for postpartum QOL.

\section{Individual in-depth interview with postpartum women}

In-depth interviews were conducted combined with local at-home postpartum check-ups by Maternal and Child Health Hospital staff in Laishui County, Hebei Province and Space Center Hospital staff in Beijing. All women who met the inclusion criteria (0-12 months after delivery, and willing to take the interview) in these two hospitals' administrative districts were interviewed. The interview content focused on what the main factors were that affected their QOL after childbirth. With the approval of the participants, the interviews were tape recorded.

\section{Focus group discussion with postpartum women}

In Laishui County, we had discussions with three focus groups: women 0-4 months after delivery, 4-6 months after delivery, and 6-12 months after delivery. There were 4-6 participants in each group. The discussions included not only the content of the in-depth interview above, but also participants' opinions about other mothers' lives. With the approval of the participants, the discussions were tape recorded.

\section{Participant observation}

The authors stayed with families with a 0- to 12-month-old child for an entire day to observe a postpartum woman's 
daily life. During this day with the family, we were able to get more sensitive information. With the approval of the families, most of the discussions about mothers' QOL were tape recorded.

\section{Expert and female health care worker consultation}

A wider, more informal consultation was undertaken with professionals and female health care workers in Laishui County and Beijing. We sent them an e-mail to introduce the research, what we wanted to discuss, and guidelines on how to give their feedback. They were asked to write down their opinions on what the important issues of postpartum women's lives influenced by childbirth are and which issues should be included in the questionnaire, and send them back to us by e-mail or mail. We then compiled notes from all the opinions without changing their original meaning.

\section{Review of existing literature}

To supplement the above means of item generation, a literature review was performed. The following databases were searched for any issue related to the effects of childbirth on the QOL of the postpartum woman: MEDLINE, PubMed, EMBASE, ProQuest, ScienceDirect OnSite, SPRINGER, CNKI. We clipped and pasted all the key sentences or paragraphs into a single WORD file.

After the tapes and notes were collected, we transcribed the tapes into the WORD file. Each transcript or note was clearly marked with the name of the interviewee, expert or health care worker, the date and place and any other relevant details.

We then reviewed all these transcripts and notes, and highlighted key phrases about issues related to QOL. We analyzed all the key phrases and cut out and pasted together all the key phrases on a single area, using area heading.

According to the results of this qualitative data analysis, we wrote down as many items as we could. We tried to use the mothers' own words from the transcript as much as possible. The answer options for these items used fivepoint Likert scales, containing response categories concerned with Intensity [such as "(1) Not at all, (2) Slightly, (3) Moderately, (4) Very, (5) Extremely"], Frequency [such as "(1) Never, (2) Rarely, (3) Sometimes, (4) Often, (5) Always"] and Evaluation [such as "(1) Very dissatisfied, (2) Dissatisfied, (3) Neither satisfied nor dissatisfied, (4) Satisfied, (5) Very satisfied"]. The PQOL domains were scored as summed rating domains and transformed on a 0 100 scale, with 0 indicating the poorest QOL and 100 indicating the best QOL. At the end of this phase, a primary item pool was generated.
Item pool modification

This phase included two steps.

\section{Item pool modification 1}

The aim of this step was to identify potential problems of acceptability, relevance, and comprehension, and then to revise the primary item pool. Maternal health experts were invited to review the items already generated, check for other issues previously overlooked, modify the questionnaire as necessary, and determine the optimum phrasing for each question.

\section{Item pool modification 2}

Furthermore, we interviewed women 0-12 months after delivery to improve the item pool revised in modification 1 . Participants were asked to identify any questions they thought were irrelevant, difficult, confusing, annoying, upsetting, or repetitive. Moreover, they were asked to read the questions carefully, and make any revisions to the phrasing and syntax to be more consistent with their speaking style. Based on the analyses, some new items were generated and added to the already existing ones, some items were dropped, and some items were revised to make the question more easy to understand and more relevant.

By the end of this phase, the final item pool was determined, and the authors believed that a high level of content validity had been achieved and so were confident that no conceptually new issues would arise and no further major refinements would be necessary.

\section{Item selection}

\section{Materials}

Data for item selection were generated in two ways: expert interview and a field survey among postpartum women.

We invited experts to review and score each item, which quantified the subjective opinion about the importance of each item. The importance of each item was scored using a 0-100 scale, with 0 indicating the least importance and 100 indicating the most importance. We then interviewed each expert to better understand his or her opinions on why the items were important or not.

In addition, we conducted a field survey using the item pool as modified in the last step in two fields (Laishui and Beijing). We took a convenience sample from mothers taking their babies for vaccination or other clinic services. The entry criteria included: mothers had to be 18 years or older, at 0-12 months after childbirth, and able to complete 
a self-reporting questionnaire. About $10 \%$ of the participants were retested after about 2 weeks. All tests were completed in the clinics by participants themselves.

\section{Statistic and selection criteria}

Based on the data collected from the experts and the field survey, items were analyzed for inclusion in the final questionnaire by seven independent measures: expert scoring method, a score for item importance, factor analysis method-factor load, coefficient of variation method-coefficient of variation, item-removed Cronbach's alpha method-Cronbach's alpha of a domain after removing an item from it, item-expected domain correlation method-correlation coefficient of an item with its expected domain, item-unexpected domain correlation method-number of high correlations with unexpected domains, and test-retest correlation method-a test-retest correlation coefficient. All of these were carried out to evaluate the item performance and to rank the items on the basis of reliability and validity. Each analysis independently answered the question: "Should this item be retained?" If at least five of the seven analyses concluded the item should be retained, then the item was retained. All statistics were done by Statistical Package for Social Sciences (SPSS 13.0).

\section{Expert Scoring Method}

This method chooses items according to their importance. As mentioned before, we invited experts to score each item for importance using a 0-100 scale. We calculated the average score of importance for each item, and then ranked the average scores. The items with an average score higher than all items' mean score were recommended for retention.

\section{Factor Analysis Method}

Principal components factor analysis with VARIMAX rotation was used to choose items according to their representativeness. If the load of the item on its expected domain was higher than the pre-set standard of 0.3 , then this item was recommended for retention.

\section{Coefficient of Variation Method}

Coefficient of variation (CV) was used to compare item variation to avoid the influence of different means of data sets in our study. The formula is: $\mathrm{CV}=(S / \bar{X}) \times 100 \%$, $S=$ standard deviation, $\bar{X}=$ Mean. If CV of the item was higher than the average $\mathrm{CV}$ of all items, then this item was recommended for retention.

\section{Item-Removed Cronbach's Alpha Method}

This method chooses items according to the influence on internal consistency of domains after removing a single item. First, we statistic the "alpha if removed" for each individual item. Then we ranked these "alpha if removed". If "alpha if removed" for one item was lower than that for other items, we concluded that removing this item would relatively much lower the internal consistency. So, the lower the item-removed Cronbach's alpha, the stronger the recommendation to retain the item.

\section{Item-Expected Domain Correlation Method}

This method chooses items according to their representativeness. We calculated the correlation coefficient between an item and its expected domain one by one. If the correlation coefficient was higher than a pre-set 0.4 , then the item was considered to be representative and this item was recommended for retention.

\section{Item-Unexpected Domain Correlation Method}

This method chooses items according to their independence. We calculated the correlation coefficient between an item and other unexpected domains and counted with how many unexpected domains the item had a high correlation $(r>0.4)$. If the item had a high correlation with two or more unexpected domains, respectively, then this item was recommended for removal.

\section{Test-Retest Correlation Method}

This method chooses items according to their stability. As mentioned before, we retested the modified item pool in a small group after about 2 weeks. We examined the correlation between the first test and the retest. If the test-retest correlation coefficient was higher than the pre-set 0.7 , then this item was recommended for retention.

\section{Results}

A primary item pool with 167 items was developed

In the item pool development phase, 28 and 24 women in Laishui and Beijing, respectively, participated in the individual in-depth interview. Time after childbirth among these women ranged from 8 days to 12 months. Another 16 families with a 0 - to 12-month-old child accepted the 1-day visit. Six professionals and 15 female health care workers in Laishui and Beijing participated in the consultation and 
provided their opinions on important QOL issues of women 0-12 months after delivery.

Important issues obtained from the qualitative methods were grouped into four categories: child care, physical function, psychological function and social support. Child care refers to the mothers' feelings about their child, including his or her physical health, accidents, development, character, and feeding; physical function refers to the mothers' perception of contraception, sleeping, rest, energy, pain, sex life, ability to work, and body image; psychological function refers to the mothers' perception of confidence in good child care, attitude towards child care, role adaptation, negative feelings, and positive feelings; social support refers to the mothers' social activities, family relationships, chores/childcare help, house environment, family economy, and outside environment.
In total, after the analysis, 167 items were generated for inclusion into the primary item pool.

\section{A 101-revised-item pool was determined}

In the item pool modification phase, ten maternal health experts and 15 women 0-12 months after childbirth from the Maternal and Child Hospital in Laishui took part.

Experts believed and mothers found most of the 167 items in the primary item pool easy to understand, but did identify some difficult ones. According to their suggestions, we dropped 75 useless or disturbing items, revised 25 unclear items, and generated nine new items. Thus, a revised item pool with 101 items was obtained. Figure 1 shows the structure of the 101-revised-item pool.
Fig. 1 Structure of the 101revised-item pool

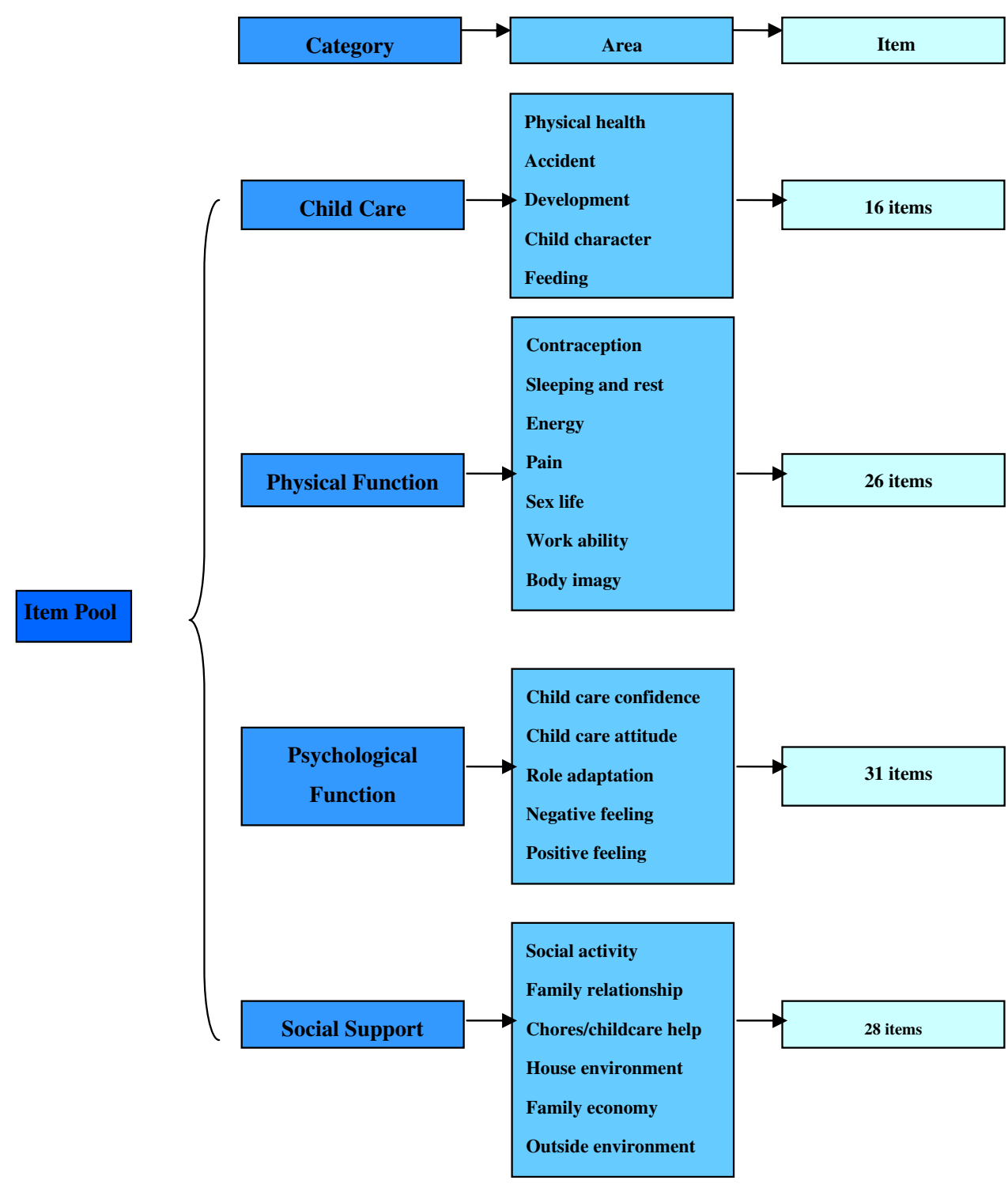


The PQOL with 60 items was formed

In the item-selection phase, ten experts reviewed the 101 items and gave them importance scores. In addition, a total of 200 postpartum women all 0-12 months after delivery (100 in Beijing and 100 in Laishui) were tested with the 101-item pool, and 20 of them were retested after about 2 weeks.

The range of urban women's age was 19.6-39.3 years, with a median age of 30.4. The range of rural women's age was 19.5-37.5 years, with a median of 25.7. Only $1.0 \%$ of urban participants had an education lower than primary school, while $10.2 \%$ of rural participants did. About $62.0 \%$ of urban and $54.5 \%$ of rural participants had a Caesarian section. About $90.0 \%$ of the urban participants had only one child, while $66.2 \%$ of the rural ones did. The completion rate of the questionnaire was $99.8 \%$.

Based on the importance scores and data from the test with the 101-item pool, 60 items were recommended for retention by at least five of the seven tests. These 60 items were selected. Here is an example of one item that was selected:

CH11 Do you worry that your child will fall sick?

(1) Never (2) Rarely (3) Sometimes (4) Often

(5) Always

Expert Scoring: the average importance score of the item was 91.00, which was higher than the mean score of all items (87.3). So this analysis concluded that this item should be retained. Factor analysis: the results of the factor analysis revealed that the load of this item on child care domain was 0.401 , which was higher than the pre-set standard of 0.3. So this analysis also concluded that this item should be retained. Coefficient of variation: $\mathrm{CV}$ of this item was 0.3746 , which was higher than the average (0.2642). So this analysis also concluded that this item should be retained. Item-removed Cronbach's alpha: the Cronbach's alpha of child care domain was 0.6666 after removing this item, which was lower than when after removing other items $(0.6740,0.6785,0.6849,0.6675$, $0.6809,0.6736,0.6789,0.6988,0.6746,0.6952,0.6894$, $0.6848,0.6964,0.6945$, and 0.6772 , respectively), indicating that removing this item would greatly lower the internal consistency (the overall Cronbach's alpha of child care domain was 0.7060 ). So, this analysis also concluded that this item should not be removed. Item-expected domain correlation: the correlation coefficient between this item and child care domain was $0.546(>0.4)$, which indicated that this item was representative, so this item should be retained. Item-unexpected domain correlation: the correlation coefficient between this item and physical function, psychological function and social support domain were $0.099,0.147$, and 0.158 , respectively (all <0.4), which indicated that this item was independent, so this item should be retained. Test-retest correlation: the test-retest correlation coefficient was $0.905(>0.7)$, so this item should be retained. All seven screening methods concluded that item $\mathrm{CH} 11$ should be retained, which indicated that this item possessed many good traits.

The number of items retained by the seven screening methods independently were: experts scoring, 62 items; factor analysis, 58 items; coefficient of variation, 52 items; item-removed Cronbach's alpha, 51 items; item-expected domain correlation, 75 items; item-unexpected domain correlation, 92 items; and test-retest correlation, 90 items. According to the rule that any item retained by at least five of the screening methods should be included, 60 items were selected.

The 60-item self-administered questionnaire grouped into four domains (child care, physical function, psychological function, and social support) and 20 subject areas. Compared to the 101-item pool, the areas of sex life, child care attitude, and child character were deleted in the 60item PQOL, since there was no item in these areas that was retained during at least five of the seven selections.

The streamlined PQOL with 40 items was formed

In order to further streamline the survey tool, we selected two items for each of the 20 subject areas, resulting in a total of 40 items in the streamlined PQOL, the structure of which is shown in Fig. 2. If more than two items scored the same in terms of the criteria for retention, we selected the two items whose meanings were closer to each other to achieve higher internal consistency. Screening results are shown in Tables 1 and 2.

The flow diagram in Fig. 3 shows the results for each step.

\section{Discussion and conclusions}

The design of this 40-item PQOL was based on a standard development procedure for a specific QOL tool [28]. The content validity of the PQOL is ensured by using a wideranging collection of postpartum QOL issues.

In this study, we focused on groups of women at different postpartum phases because in our previous study we found that issues related to having had a baby were very similar across different groups of women. The qualitative results of the interviews conducted during this study showed this again. Although respondents at different postpartum stages did have physiological differences, what they considered as the most important issues for their QOL were similar, including the health of the baby, opportunities for them to rest and support from other family members. This phenomenon might well be strongly 
Fig. 2 Structure of the PQOL

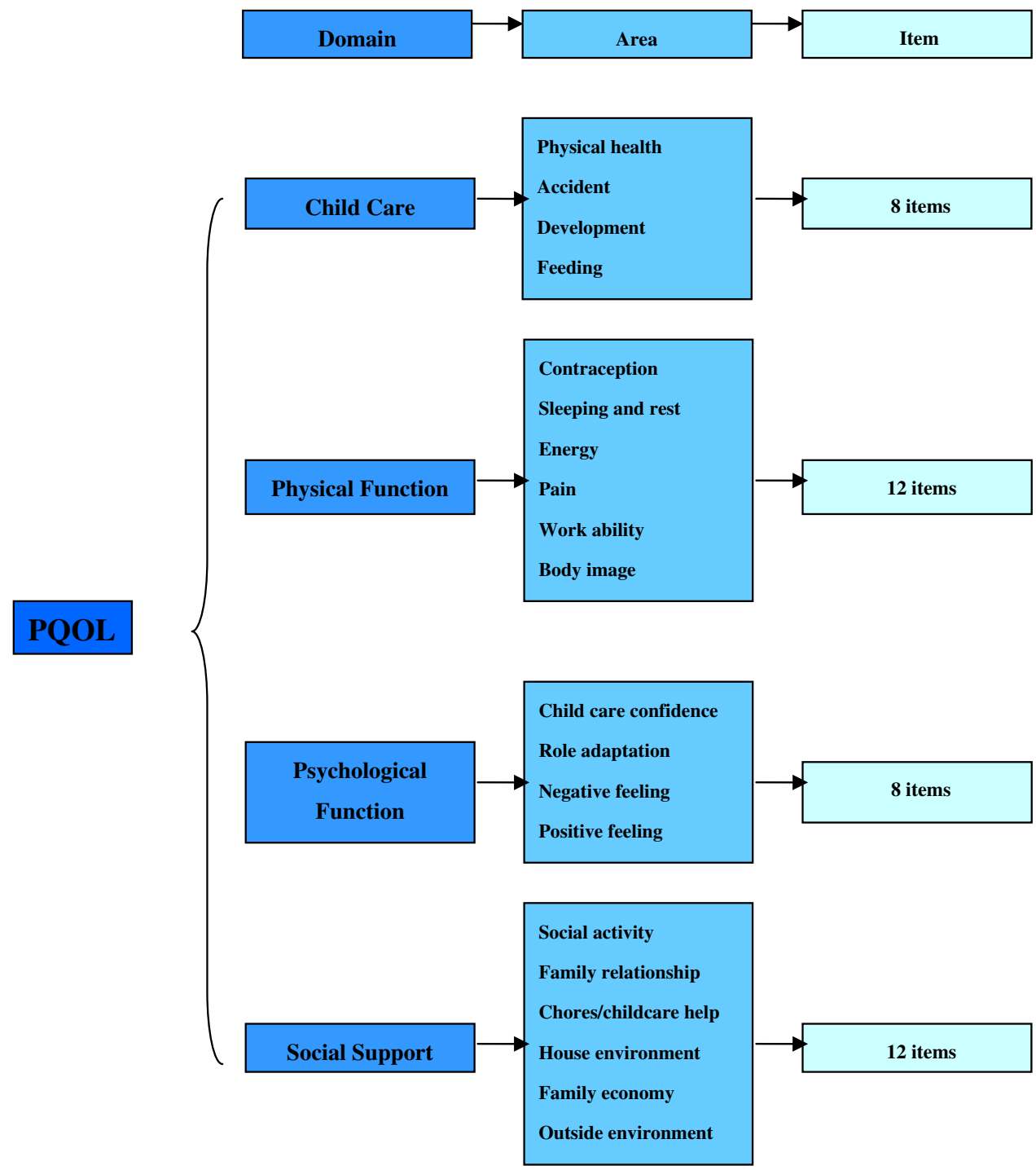

influenced by the culture and social structures of modernday China. Some issues are consistently identified as important topics throughout the different postpartum stages of the women's lives, such as the "only child" phenomenon and the relationship with the husband's family. While focusing on women at different points in their first postpartum year may have resulted in different mean scores of QOL for different groups of women, we believe that this does not influence the internal consistency of the tool.

The PQOL contained physical function and psychological function domain, in which some areas (e.g., sleep, energy, positive and negative feeling) were close to other well-developed QOL scales [17]. However, some areas and items considered important in other scales were excluded (e.g., appetite), some specific areas and items were added (e.g., confidence in child care and maternal role adaptation area were added to psychological function domain, and item-"Are you happy being a mother?" was added to the positive feeling area). Moreover, new additional domains, which were considered crucial in influencing postpartum QOL, were added (child care and social support domain). Although these two were "new" domains, the areas included in them were common issues of concern to both researchers and postpartum women. For example, an issue with breast-feeding has been frequently reported [29]. The specific domains or areas may help in identifying causes to an impairment of QOL specifically related to childbirth and may allow female health care workers and researchers to design appropriate interventions.

There are irreconcilable demands in designing the questionnaire: we want both maximum validity and reliability and universal acceptance. We hope to generate as many items as possible to cover all QOL issues to achieve maximum validity and reliability, but the great number of items would present a major problem - the extreme length of an assessment would preclude its use in many clinical 
Table 1 Results of different screening methods

\begin{tabular}{|c|c|c|c|c|c|c|c|}
\hline $\begin{array}{l}\text { Item } \\
\text { code }\end{array}$ & $\begin{array}{l}\text { Expert } \\
\text { scoring }\end{array}$ & $\begin{array}{l}\text { Factor } \\
\text { analysis }\end{array}$ & $\begin{array}{l}\text { Coefficient of } \\
\text { variation }\end{array}$ & $\begin{array}{l}\text { Item-removed } \\
\text { Cronbach's alpha }\end{array}$ & $\begin{array}{l}\text { Item-expected } \\
\text { domain } \\
\text { correlation }\end{array}$ & $\begin{array}{l}\text { Item-unexpected } \\
\text { domain } \\
\text { correlation }\end{array}$ & $\begin{array}{l}\text { Test-retest } \\
\text { correlation }\end{array}$ \\
\hline CH11 & 91.00 & 0.401 & 0.3746 & 0.6666 & 0.546 & 0 & 0.905 \\
\hline $\mathrm{CH} 12$ & 88.88 & 0.315 & 0.1675 & 0.6740 & 0.510 & 0 & 0.862 \\
\hline $\mathrm{CH} 21$ & 79.25 & 0.385 & 0.3440 & 0.6785 & 0.471 & 0 & 0.927 \\
\hline $\mathrm{CH} 22$ & 76.88 & 0.391 & 0.3352 & 0.6849 & 0.382 & 0 & 0.923 \\
\hline CH31 & 87.88 & 0.501 & 0.4044 & 0.6675 & 0.537 & 0 & 0.954 \\
\hline CH32 & 73.50 & 0.548 & 0.3813 & 0.6809 & 0.464 & 0 & 0.877 \\
\hline $\mathrm{CH} 41$ & 85.75 & -0.032 & 0.3923 & 0.6988 & 0.402 & 0 & 0.940 \\
\hline $\mathrm{CH} 42$ & 91.00 & 0.292 & 0.2172 & 0.6772 & 0.458 & 0 & 0.887 \\
\hline PH11 & 90.88 & 0.219 & 0.3006 & 0.8336 & 0.355 & 0 & 1.000 \\
\hline PH12 & 88.13 & 0.318 & 0.3058 & 0.8316 & 0.389 & 0 & 0.929 \\
\hline PH21 & 89.75 & 0.225 & 0.3002 & 0.8274 & 0.488 & 0 & 0.909 \\
\hline PH22 & 87.50 & 0.336 & 0.3852 & 0.8239 & 0.570 & 1 & 0.565 \\
\hline PH31 & 91.75 & 0.409 & 0.3408 & 0.8235 & 0.580 & 0 & 0.818 \\
\hline PH32 & 89.75 & 0.350 & 0.2875 & 0.8230 & 0.601 & 3 & 0.887 \\
\hline PH41 & 88.00 & 0.459 & 0.2861 & 0.8235 & 0.579 & 0 & 0.956 \\
\hline PH42 & 90.63 & 0.379 & 0.2770 & 0.8257 & 0.530 & 0 & 0.864 \\
\hline PH51 & 88.14 & 0.644 & 0.2741 & 0.8299 & 0.433 & 0 & 0.839 \\
\hline PH52 & 90.86 & 0.646 & 0.2130 & 0.8289 & 0.447 & 0 & 0.719 \\
\hline PH61 & 90.13 & 0.181 & 0.3831 & 0.8285 & 0.467 & 0 & 0.917 \\
\hline PH62 & 85.50 & 0.079 & 0.4043 & 0.8293 & 0.441 & 0 & 0.906 \\
\hline PS11 & 88.00 & 0.637 & 0.3071 & 0.9001 & 0.606 & 1 & 0.781 \\
\hline PS12 & 88.63 & 0.377 & 0.2676 & 0.9017 & 0.504 & 0 & 0.968 \\
\hline PS21 & 89.50 & 0.697 & 0.1608 & 0.9001 & 0.616 & 0 & 0.765 \\
\hline PS22 & 92.25 & 0.667 & 0.1767 & 0.9007 & 0.562 & 0 & 0.867 \\
\hline PS31 & 92.25 & 0.608 & 0.1654 & 0.8995 & 0.639 & 0 & 0.968 \\
\hline PS32 & 90.75 & 0.358 & 0.3342 & 0.9005 & 0.594 & 1 & 0.689 \\
\hline PS41 & 92.00 & 0.761 & 0.1561 & 0.9005 & 0.586 & 0 & 0.947 \\
\hline PS42 & 92.63 & 0.642 & 0.1751 & 0.9000 & 0.611 & 1 & 1.000 \\
\hline SO11 & 79.00 & 0.479 & 0.3656 & 0.8725 & 0.608 & 2 & 0.860 \\
\hline SO12 & 78.75 & 0.415 & 0.3302 & 0.8739 & 0.562 & 1 & 0.739 \\
\hline SO21 & 92.00 & 0.475 & 0.2180 & 0.8740 & 0.556 & 0 & 0.950 \\
\hline $\mathrm{SO} 22$ & 93.38 & 0.475 & 0.2211 & 0.8733 & 0.588 & 1 & 0.939 \\
\hline SO31 & 91.00 & 0.561 & 0.3017 & 0.8715 & 0.639 & 0 & 0.822 \\
\hline SO32 & 89.13 & 0.577 & 0.2899 & 0.8735 & 0.575 & 0 & 1.000 \\
\hline SO41 & 85.00 & 0.539 & 0.2762 & 0.8742 & 0.551 & 0 & 0.820 \\
\hline $\mathrm{SO} 42$ & 89.88 & 0.572 & 0.2870 & 0.8724 & 0.611 & 0 & 0.729 \\
\hline SO51 & 88.00 & 0.581 & 0.2782 & 0.8717 & 0.634 & 1 & 0.981 \\
\hline SO52 & 93.75 & 0.529 & 0.2775 & 0.8737 & 0.571 & 0 & 0.970 \\
\hline SO61 & 79.63 & 0.509 & 0.2991 & 0.8771 & 0.434 & 0 & 0.818 \\
\hline SO62 & 80.75 & 0.394 & 0.2526 & 0.8770 & 0.433 & 0 & 0.973 \\
\hline
\end{tabular}

Data in the expert scoring column is the average score of item importance; data in the factor analysis column is item load on the factor to which the item hypothetically belonged; data in the coefficient of variation column is CV of item; data in the item-removed Cronbach's alpha column is the Cronbach's alpha of the corresponding domain after removing the item; data in the item-expected domain correlation column is the correlation coefficient between the item and its corresponding domain; data in the item-unexpected domain correlation column is the number of correlation coefficients higher than 0.4; data in the test-retest correlation column is the correlation coefficient between the test and retest

$\mathrm{CH}$ child care domain; $\mathrm{PH}$ physical function domain; $\mathrm{PS}$ psychological function domain; $S O$ social support domain 
Table 2 Items selected for the PQOL

\begin{tabular}{|c|c|}
\hline Code & Item \\
\hline CH11 & $\begin{array}{l}\text { Do you worry that your child will fall sick? } \\
\text { (1) Never (2) Rarely (3) Sometimes (4) Often (5) Always }\end{array}$ \\
\hline $\mathrm{CH} 12$ & $\begin{array}{l}\text { How satisfied are you with your child's health? } \\
\text { (1) Very dissatisfied (2) Dissatisfied (3) Neither satisfied nor dissatisfied (4) Satisfied (5) Very satisfied }\end{array}$ \\
\hline $\mathrm{CH} 21$ & $\begin{array}{l}\text { Do you worry that your child will have an accident? } \\
\text { (1) Never (2) Rarely (3) Sometimes (4) Often (5) Always }\end{array}$ \\
\hline $\mathrm{CH} 22$ & $\begin{array}{l}\text { How much do you take pains to prevent an accident to your child? } \\
\text { (1) Not at all (2) A little (3) A moderate amount (4) Very much (5) An extreme amount }\end{array}$ \\
\hline CH31 & $\begin{array}{l}\text { Do you worry about the nutrition of your child? } \\
\text { (1) Never (2) Rarely (3) Sometimes (4) Often (5) Always }\end{array}$ \\
\hline $\mathrm{CH} 32$ & $\begin{array}{l}\text { Do you worry that your child is not smart? } \\
\text { (1) Never (2) Rarely (3) Sometimes (4) Often (5) Always }\end{array}$ \\
\hline $\mathrm{CH} 41$ & $\begin{array}{l}\text { Do you think that your breast milk is enough for your child? } \\
\text { (1) Not enough at all (2) Not enough (3) Sometimes (4) Enough (5) Always enough }\end{array}$ \\
\hline $\mathrm{CH} 42$ & $\begin{array}{l}\text { How satisfied are you with current feeding? } \\
\text { (1) Very dissatisfied (2) Dissatisfied (3) Neither satisfied nor dissatisfied (4) Satisfied (5) Very satisfied }\end{array}$ \\
\hline PH11 & $\begin{array}{l}\text { Do you worry about unexpected pregnancy? } \\
\text { (1) Never (2) Rarely (3) Sometimes (4) Often (5) Always }\end{array}$ \\
\hline PH12 & $\begin{array}{l}\text { How much are you bothered by contraception? } \\
\text { (1) Not at all (2) Slightly (3) Moderately (4) Very (5) Extremely }\end{array}$ \\
\hline PH21 & $\begin{array}{l}\text { How satisfied are you with your sleep? } \\
\text { (1) Very dissatisfied (2) Dissatisfied (3) Neither satisfied nor dissatisfied (4) Satisfied (5) Very satisfied }\end{array}$ \\
\hline PH22 & $\begin{array}{l}\text { Do you have enough time to rest? } \\
\text { (1) Never (2) Rarely (3) Sometimes (4) Often (5) Always }\end{array}$ \\
\hline PH31 & $\begin{array}{l}\text { How easily do you get tired? } \\
\text { (1) Not at all (2) Slightly (3) Moderately (4) Very (5) Extremely }\end{array}$ \\
\hline PH32 & $\begin{array}{l}\text { How satisfied are you with the energy that you have? } \\
\text { (1) Very dissatisfied (2) Dissatisfied (3) Neither satisfied nor dissatisfied (4) Satisfied (5) Very satisfied }\end{array}$ \\
\hline PH41 & $\begin{array}{l}\text { Does physical pain influence your daily life? } \\
\text { (1) Never (2) Rarely (3) Sometimes (4) Often (5) Always }\end{array}$ \\
\hline PH42 & $\begin{array}{l}\text { How much do you think that your physical health has been affected by childbirth? } \\
\text { (1) Not at all (2) Slightly (3) Moderately (4) Very (5) Extremely }\end{array}$ \\
\hline PH51 & $\begin{array}{l}\text { How much conflict do you feel between child care and work? } \\
\text { (1) Not at all (2) Slightly (3) Moderately (4) Very (5) Extremely }\end{array}$ \\
\hline PH52 & $\begin{array}{l}\text { Has your child caused you to be distracted and worried at work? } \\
\text { (1) Not at all (2) Slightly (3) Moderately (4) Very (5) Extremely }\end{array}$ \\
\hline PH61 & $\begin{array}{l}\text { How satisfied are you with the way your body looks? } \\
\text { (1) Very dissatisfied (2) Dissatisfied (3) Neither satisfied nor dissatisfied (4) Satisfied (5) Very satisfied }\end{array}$ \\
\hline PH62 & $\begin{array}{l}\text { Do you feel blue by your looks? } \\
\text { (1) Never (2) Rarely (3) Sometimes (4) Often (5) Always }\end{array}$ \\
\hline PS11 & $\begin{array}{l}\text { How much confidence do you have in caring for your baby well? } \\
\text { (1) Not at all (2) A little (3) A moderate amount (4) Very much (5) An extreme amount }\end{array}$ \\
\hline PS12 & $\begin{array}{l}\text { How much child care skill do you think you have? } \\
\text { (1) Not at all (2) A little (3) A moderate amount (4) Very much (5) An extreme amount }\end{array}$ \\
\hline PS21 & $\begin{array}{l}\text { Are you interested in your child? } \\
\text { (1) Never (2) Rarely (3) Sometimes (4) Often (5) Always }\end{array}$ \\
\hline PS22 & $\begin{array}{l}\text { Are you willing to look after your child? } \\
\text { (1) Never (2) Rarely (3) Sometimes (4) Often (5) Always }\end{array}$ \\
\hline
\end{tabular}


Table 2 continued

\begin{tabular}{|c|c|}
\hline Code & Item \\
\hline PS31 & $\begin{array}{l}\text { Do you regret having had this child? } \\
\text { (1) Never (2) Rarely (3) Sometimes (4) Often (5) Always }\end{array}$ \\
\hline PS32 & $\begin{array}{l}\text { Is caring a baby hard for you? } \\
\text { (1) Never (2) Rarely (3) Sometimes (4) Often (5) Always }\end{array}$ \\
\hline PS41 & $\begin{array}{l}\text { Are you happy being a mother? } \\
\text { (1) Never (2) Rarely (3) Sometimes (4) Often (5) Always }\end{array}$ \\
\hline PS42 & $\begin{array}{l}\text { How much fun is your life after having this child? } \\
\text { (1) Not at all (2) Slightly (3) Moderately (4) Very much (5) Extremely }\end{array}$ \\
\hline SO11 & $\begin{array}{l}\text { Do you have enough contact with the outside world? } \\
\text { (1) Not at all (2) Slightly (3) Moderately (4) Very much (5) Extremely }\end{array}$ \\
\hline SO12 & $\begin{array}{l}\text { Do you see enough of your neighbors? } \\
\text { (1) Not at all (2) Slightly (3) Moderately (4) Very much (5) Extremely }\end{array}$ \\
\hline SO21 & $\begin{array}{l}\text { What do you think your husband's attitude is towards you? } \\
\text { (1) Very bad (2) Bad (3) Neither bad nor good (4) Good (5) Very good }\end{array}$ \\
\hline $\mathrm{SO} 22$ & $\begin{array}{l}\text { How close is the relationship between you and your husband? } \\
\text { (1) Not at all (2) Slightly (3) Moderately (4) Very (5) Extremely }\end{array}$ \\
\hline SO31 & $\begin{array}{l}\text { How much help do you get caring for your child? } \\
\text { (1) None at all (2) A little (3) A moderate amount (4) Very much (5) A great deal }\end{array}$ \\
\hline SO32 & $\begin{array}{l}\text { How much help do you get doing household chores? } \\
\text { (1) None at all (2) A little (3) A moderate amount (4) Very much (5) A great deal }\end{array}$ \\
\hline SO41 & $\begin{array}{l}\text { How clean is your house? } \\
\text { (1) Not at all (2) Slightly (3) Moderately (4) Very (5) Extremely }\end{array}$ \\
\hline SO42 & $\begin{array}{l}\text { How satisfied are you with your housing situation? } \\
\text { (1) Very dissatisfied (2) Dissatisfied (3) Neither satisfied nor dissatisfied (4) Satisfied (5) Very satisfied }\end{array}$ \\
\hline SO51 & $\begin{array}{l}\text { Is the money that yourself can decide how to spend enough? } \\
\text { (1) Not enough (2) A little short (3) Just enough (4) Enough (5) Very enough }\end{array}$ \\
\hline SO52 & $\begin{array}{l}\text { Do you worry about your finances? } \\
\text { (1) Never (2) Rarely (3) Sometimes (4) Often (5) Always }\end{array}$ \\
\hline SO61 & $\begin{array}{l}\text { How satisfied are you with your living environment, including pollution, noise, climate and location? } \\
\text { (1) Very dissatisfied (2) Dissatisfied (3) Neither satisfied nor dissatisfied (4) Satisfied (5) Very satisfied }\end{array}$ \\
\hline SO62 & $\begin{array}{l}\text { How satisfied are you with the transportation available to you? } \\
\text { (1) Very dissatisfied (2) Dissatisfied (3) Neither satisfied nor dissatisfied (4) Satisfied (5) Very satisfied }\end{array}$ \\
\hline
\end{tabular}

and research settings [30]. It is difficult for unsupervised individuals to complete an instrument that requires more than $10 \mathrm{~min}$ [31]. It took about $15 \mathrm{~min}$ to complete the 101-item pool, which meant the item pool might be too long to be well accepted. Furthermore, the item pool might also contain a large number of items which may be less relevant to postpartum QOL. The best option to obtain a reliable, valid, and acceptable questionnaire is to select subsets of items.

Researchers usually choose different methods to select the items according to the aim of the research. Some methods are applied often, such as the distribution of responses [32], item-total correlations [33], the ability to discriminate ill and well populations [34] and the results of factor analysis [35]. However, the procedure of item selection is problematic, due to the subjective component of decisions regarding inclusion or exclusion. The strategy of comprehensive selection in this study was designed to decrease the uncertainty caused by this subjective nature, and to enable the whole questionnaire to be valid and reliable. The benefit of the comprehensive strategy has been reported in other research [36].

\section{Conclusions}

This is the first attempt to design a Chinese QOL measurement for postpartum women (PQOL) through a standard development process. The instrument has an interpretable and multi-area factor structure. Four domains 


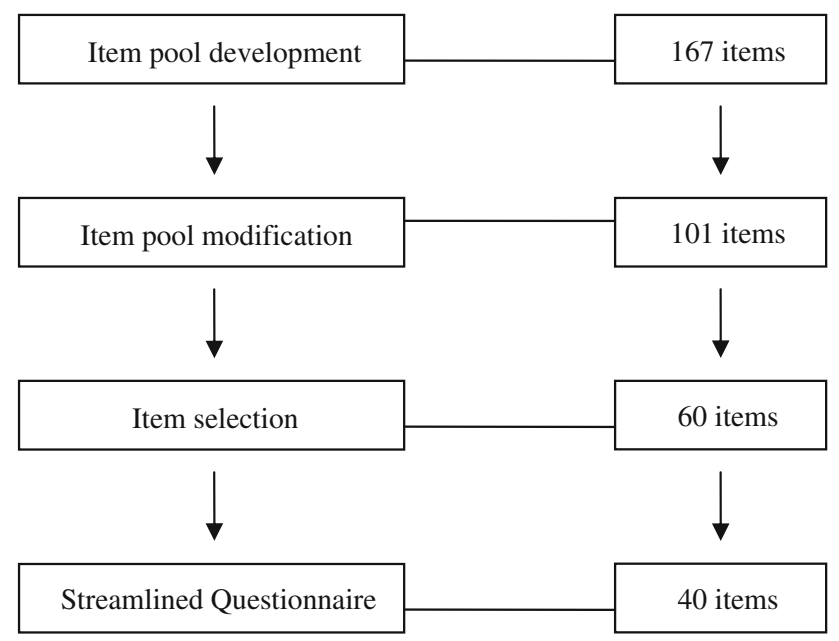

Fig. 3 Results of each step in the questionnaire design

appeared: child care (eight items), physical function (12 items), psychological function (eight items), and social support (12 items). The validity and reliability need to be established in the future. However, we took a big step in developing a Chinese QOL questionnaire for postpartum women. We recommend that this QOL questionnaire be translated and undergo cross-cultural validation, because it could be used to great effect in other countries and cultures, particularly other East Asian cultures.

Acknowledgments The authors wish to express their appreciation for the support and sponsorship received from Maternal and Child Hospital of Laishui County, Hebei Province, and the Space Center Hospital of Beijing. We also wish to thank Wang Jing, Wang Jin-Lan, and Gao Ya-Ping for technical and administrative coordination, and all the other experts and health care workers for technical work, and Dr. Jeffrey McFarland for language editing and helpful suggestions.

Open Access This article is distributed under the terms of the Creative Commons Attribution Noncommercial License which permits any noncommercial use, distribution, and reproduction in any medium, provided the original author(s) and source are credited.

\section{References}

1. Glazener, C. M., Abdalla, M., Stroud, P., et al. (1995). Postnatal maternal morbidity: extent, causes, prevention and treatment. British Journal of Obstetrics and Gynaecology, 102(4), 282-287.

2. Patel, V., Rahman, A., Jacob, K. S., et al. (2004). Effect of maternal mental health on infant growth in low-income countries: new evidence from South Asia. British Medical Journal, 328(7443), 820-823. doi:10.1136/bmj.328.7443.820.

3. WHO.UNICEF, \& UNFPA. (2003). Maternal mortality in 2000: estimates developed by WHO, UNICEF, and UNFPA. Geneva: WHO.

4. Li, Y.-R., Fu, S.-Q., \& Cui, X.-L. (2005). Postnatal sexual problems and related factors analysis. Maternal and Child Health Care of China, 20(3), 334-336.

5. Zhou, S.-Z., Wang, X.-L., Wang, Y., et al. (2006). Study of postpartum traditional practices and pain of women in rural Hebei
Province. Maternal and Child Health Care of China, 21(19), 2708-2710.

6. Williams, A., Herron-Marx, S., \& Carolyn, H. (2007). The prevalence of enduring postnatal perineal morbidity and its relationship to perineal trauma. Midwifery, 23(4), 392-403. doi: 10.1016/j.midw.2005.12.006.

7. Glazener, C. M., Herbison, G. P., MacArthur, C., et al. (2005). Randomized controlled trial of conservative management of postnatal urinary and faecal incontinence: six year follow up. BMJ (Clinical Research Ed.), 330(7487), 337. doi:10.1136/bmj. 38320.613461 .82$.

8. Kirkland, V. L., Palmer, M. H., \& Fitzgerald, S. T. (2001). Incontinence in a manufacturing setting: women's perceptions and responses. Public Health Nursing (Boston, Mass.), 18(5), 312-317. doi:10.1046/j.1525-1446.2001.00312.x.

9. Michalaka, E. E., Tama, E. M., Manjunatha, C. V., et al. (2004). Generic and health-related quality of life in patients with seasonal and nonseasonal depression. Psychiatry Research, 128, 245-251. doi:10.1016/j.psychres.2004.01.012.

10. World Health Organization. (1997). WHOQOL: Measuring quality of life. Geneva: WHO.

11. Aprile, I., Di Stasio, E., Romitelli, F., et al. (2008). Effects of rehabilitation on quality of life in patients with chronic stroke. Brain Injury: [BI], 22(6), 451-456. doi:10.1080/02699050802060639.

12. Jayadevappa, R., Johnson, J. C., \& Bloom, B. S. (2007). Effectiveness of transcendental meditation on functional capacity and quality of life of African Americans with congestive heart failure: a randomized control study. Ethnicity and Disease, 17(1), 72-77.

13. Jacob, M. E., Abraham, V. J., \& Abraham, S. (2007). The effect of community based daycare on mental health and quality of life of elderly in rural south India: a community intervention study. International Journal of Geriatric Psychiatry, 22(5), 445-447. doi:10.1002/gps.1706.

14. Willich, S. N., Reinhold, T., \& Selim, D. (2006). Cost-effectiveness of acupuncture treatment in patients with chronic neck pain. Pain, 125(1-2), 107-113. doi:10.1016/j.pain.2006.06.006.

15. Li, X.-Y., Zhang, H.-L., Dong, S.-Q., et al. (2005). Influence factor study of quality of life for postpartum women. Chinese Health Service Management, 21(4), 235-237.

16. Goeree, R. (1994). Evaluation of programs for the treatment of schizophrenia: a health economic perspective. Ottawa $(\mathrm{ON})$ : Health Canada.

17. World Health Organization Quality of Life Group. (1994). The development of the World Health Organization Quality of Life Assessment Instrument (WHOQOL). In J. Orley \& W. Kuyken (Eds.), Quality of life assessment: international perspectives (pp. 41-57). Berlin: Springer-Verlag.

18. Aaronson, N. K., Ahmedzai, S., Bergman, B., et al. (1993). The European Organization for research and treatment of cancer QLQ-C30: a quality-of-life instrument for use in international clinical trials in oncology. Journal of the National Cancer Institute, 85(5), 365-376. doi:10.1093/jnci/85.5.365.

19. Dooms, C. A., Pat, K. E., \& Vansteenkiste, J. F. (2006). The effect of chemotherapy on symptom control and quality of life in patients with advanced non-small cell lung cancer. Future Drugs, 6(4), 531-544.

20. Sherman, A. C., Simonton, S., \& Adams, D. C. (2000). Assessing quality of life in patients with head and neck cancer. Archives of Otolaryngology-Head \& Neck Surgery, 126(4), 459-467.

21. O’Neill, B., McKevitt, A., Rafferty, S., et al. (2007). A comparison of twice-versus once-weekly supervision during pulmonary rehabilitation in chronic obstructive pulmonary disease. Archives of Physical Medicine and Rehabilitation, 88(2), 167-172. doi: 10.1016/j.apmr.2006.11.007.

22. Taylor, R., Kirby, B., \& Burdon, D. (1998). The assessment of recovery in patients after myocardial infarction using three 
generic quality-of-life measures. Journal of Cardiopulmonary Rehabilitation, 18(2), 139-144. doi:10.1097/00008483-19980 3000-00007.

23. Hill, P., Aldag, J. C., Hekel, B., et al. (2006). Maternal postpartum quality of life questionnaire. Journal of Nursing Measurement, 14(3), 205-220. doi:10.1891/jnm-v14i3a005.

24. Symon, A. (2002). Postnatal quality of life assessment: introducing the mother-generated index. Birth (Berkeley, CA.), 29(1), 40-46. doi:10.1046/j.1523-536X.2002.00154.x.

25. Symon, A., Mackay, A., \& Ruta, D. (2003). Postnatal quality of life: a pilot study using the mother-generated index. Journal of Advanced Nursing, 42(1), 21-29. doi:10.1046/j.1365-2648.2003. 02575.x.

26. Symon, A., McGreavey, J., \& Picken, C. (2003). Postnatal quality of life assessment: validation of the mother-generated index. British Journal of Obstetrics and Gynaecology, 110, 865-868.

27. Carmines, E. G., \& Zeller, R. A. (1991). Reliability and validity assessment. Newbury Park: Sage.

28. DeVellis, R. F. (2003). Scale development: theory and applications (2nd ed.). Thousand Oaks, CA: Sage.

29. Beck, C. T. (1998). A review of research instruments for use during the postpartum period. The American Journal of Maternal Child Nursing, 23(5), 254-261. doi:10.1097/00005721-19980 9000-00008.

30. Fang, J.-Q. (2000). Measurement and application of quality of life (1st ed.). Beijing: Peking University Press.
31. Scientific Advisory Committee of the Medical Outcome Trust. (2002). Assessing health status and quality-of-life instruments: Attributes and review criteria. Quality of Life Research, 11, 193205. doi:10.1023/A:1015291021312.

32. Tennant, R., Hiller, L., Fishwick, R., et al. (2007). The WarwickEdinburgh Mental Well-being Scale (WEMWBS): Development and UK validation. Health and Quality of Life Outcomes, 5, 63. doi:10.1186/1477-7525-5-63.

33. Sayers, M. S., \& Newton, J. T. (2006). Patients' expectations of orthodontic treatment: part 1-development of a questionnaire. Journal of Orthodontics, 33, 258-269. doi:10.1179/14653120522 5021753.

34. Kahler, C. W., Strong, D. R., \& Read, J. P. (2005). Toward efficient and comprehensive measurement of the alcohol problems continuum in college students: the brief young adult alcohol consequences questionnaire. Alcoholism, Clinical and Experimental Research, 29, 1180-1189. doi:10.1097/01.ALC.000017 1940.95813.A5.

35. Wan, C.-H., Meng, Q., Luo, J.-H., et al. (2007). Development of the general module of the system of quality of life instruments for cancer patients: item selection and structure of the general module. Chinese Journal of Cancer, 26(2), 113-117.

36. Hao, Y.-T., Sun, X.-F., Fang, J.-Q., et al. (2004). The study of statistical method used for item selection. Chinese Journal of Health Statistics, 21(4), 209-211. 